\title{
APPLICATIONS OF HORADAM POLYNOMIALS TO GENERAL CLASSES OF BI-UNIVALENT FUNCTIONS INVOLVING THE $q$-DERIVATIVE OPERATOR
}

\author{
ŞAHSENE ALTINKAYA and SIBEL YALÇIN
}

\begin{abstract}
In this present investigation, by using the Horadam polynomials, we aim to build a bridge between the theory of geometric functions and that of special functions, which are usually considered very different fields. Thus, we introduce some new classes of bi-univalent functions defined by combining the $q$-derivative operator and the Horadam polynomials. Afterwards, we derive coefficient inequalities and consider the classical Fekete-Szegö problem.
\end{abstract}

MSC 2010. 11B39, 30C45.

Key words. Bi-univalent functions, Fekete-Szegö problem, Horadam polynomials, principle of subordination, recurrence relation.

\section{REFERENCES}

[1] Ş. Altınkaya and S. Yalçın, Estimates on coefficients of a general subclass of bi-univalent functions associated with symmetric q-derivative operator by means of the Chebyshev polynomials, Asia Pacific Journal of Mathematics, 4 (2017), 90-99.

[2] Ş. Altınkaya and S. Yalçın, Estimate for initial Maclaurin of general subclasses of bi-univalent functions of complex order involving subordination, Honam Math. J., 40 (2018), 391-400.

[3] D.A. Brannan and J.G. Clunie, Aspects of contemporary complex analysis, in Proceedings of an instructional conference organized by the London Mathematical Society at the University of Durham (a NATO advanced study Institute), Academic Press, New York, 1979.

[4] D.A. Brannan and T.S. Taha, On some classes of bi-univalent functions, Stud. Univ. Babeş-Bolyai Math., 31 (1986), 70-77.

[5] P.L. Duren, Univalent functions, Springer-Verlag, New York, 1983.

[6] M. Fekete and G. Szegö, Eine Bemerkung uber Ungerade Schlichte Funktionen, J. Lond. Math. Soc., s1-8 (1933), 85-89.

[7] P. Filipponi and A.F. Horadam, Derivative sequences of Fibonacci and Lucas polynomials, Applications of Fibonacci Numbers, 4 (1991), 99-108.

[8] P. Filipponi and A.F. Horadam, Second derivative sequences of Fibonacci and Lucas polynomials, Fibonacci Quart., 31 (1993), 194-204.

[9] T. Horzum and E. Gökçen Koçer, On some properties of Horadam polynomials, International Mathematical Forum, 4 (2009), 1243-1252.

The authors thank the referee for his helpful comments and suggestions.

DOI: $10.24193 /$ mathcluj.2020.1.01 
[10] A.F. Horadam and J.M. Mahon, Pell and Pell-Lucas polynomials, Fibonacci Quart., 23 (1985), 7-20.

[11] F.H. Jackson, On q-functions and a certain difference operator, Transactions of the Royal Society of Edinburgh, 46 (1908), 253-281.

[12] M. Lewin, On a coefficient problem for bi-univalent functions, Proc. Amer. Math. Soc., 18 (1967), 63-68.

[13] A. Lupas, A guide of Fibonacci and Lucas polynomials, Octagon Mathematics Magazine, 7 (1999), 2-12.

[14] E. Netanyahu, The minimal distance of the image boundary from the origin and the second coefficient of a univalent function in $|z|<1$, Arch. Ration. Mech. Anal., 32 (1969), 100-112.

[15] Ch. Pommerenke, Univalent functions, Vandenhoeck \& Ruprecht, Göttingen, 1975.

[16] H.M. Srivastava, Univalent functions, fractional calculus, and associated generalized hypergeometric functions, in Univalent Functions, Fractional Calculus, and Their Applications, H. M. Srivastava and S. Owa, Editors, Halsted Press, John Wiley and Sons, New York, 1989.

[17] H.M. Srivastava, G. Murugusundaramoorthy and N. Magesh, Certain subclasses of biunivalent functions associated with the Hohlov operator, Appl. Math. Lett., 1 (2013), $67-73$.

[18] H.M. Srivastava, A.K. Mishra and P. Gochhayat, Certain subclasses of analytic and bi-univalent functions, Appl. Math. Lett., 23 (2000), 1188-1192.

[19] P. Vellucci and A.M. Bersani, The class of Lucas-Lehmer polynomials, Rend. Mat. Appl., 37 (2016), 43-62.

[20] T. Wang and W. Zhang, Some identities involving Fibonacci, Lucas polynomials and their applications, Bull. Math. Soc. Sci. Math. Roumanie, 55 (2012), 95-103.

Received February 5, 2019

Accepted October 16, 2019

\author{
Bursa Uludag University \\ Department of Mathematics \\ Bursa, Turkey \\ E-mail: sahsenealtinkaya@gmail.com \\ E-mail: syalcin@uludag.edu.tr
}

